\title{
Comparison of Measurements and Theory For Backscatter From Bare and Snow-Covered Saline Ice
}

\author{
JONATHAN W. BREDOW AND SIVAPRASAD GOGINENI
}

\begin{abstract}
C-band backseatter measurements were made on artificially grown sea ice at the U.S. Army Cold Regions Research and Engineering Laboratory (CRREL) during the winters of 1987-1988 and 1988-1989. These measurements were made on smooth, rough, and snow-covered saline ice. The measured $\sigma^{\circ}(\theta)$ of smooth saline ice (rms height $<0.05 \mathrm{~cm}$ ) disagreed with small perturbation method (SPM) surface scattering predictions. Using physical parameters of the ice in a simple layer model, we show that this discrepancy can be explained by scattering from beneath the surface. $A$ thin $(7-\mathrm{cm})$ dry snow cover had a significant influence on backscatter from the smooth ice sheet. This influence was due to scattering from particles within the snow and can be predicted by a commonly used empirical layer model for snow. The results of backscatter measurements of a moderately rough saline ice sheet were found to agree with SPM predictions.
\end{abstract}

\section{INTRODUCTION}

$I^{T}$ T WAS first reported about 20 years ago that radars are useful for remote monitoring of polar regions [1]-[4]. These early studies indicated the potential for obtaining sea ice parameters, such as ice type and movement, and the location of ridges from radar images. Radars are currently being used operationally to monitor some of these parameters with radar; e.g., Hagman [5], Gedney [6], and Loshchilov [7]. However, quantitative interpretation of radar images has been hampered by a poor understanding of how microwaves interact with sea ice. Attempts to relate backscatter measurements conducted in the field with physical parameters of ice have met with limited success. Field trips into ice-infested waters are difficult and expensive. In addition, the high degree of variability found in the field has made the task of correlating radar measurements with physical parameters of the ice extremely difficult. To circumvent these difficulties a laboratory facility was established at the U.S. Army Cold Regions Research and Engineering Laboratory (CRREL) in Han-

Manuscript received November 5, 1989; revised February 21, 1990. This work was partially supported by the Office of Naval Research, and by. the National Aeronautics and Space Administration through Grant N00014$89-\mathrm{J}-1456$.

J. W. Bredow was with the Radar Systems and Remote Sensing Laboratory, University of Kansas, Lawrence, KS. He is now with the Department of Electrical and Computer Engineering, University of Texas, Arlington, TX76019.

S. Gogineni is with the Radar Systems and Remote Sensing Laboratory, University of Kansas, 2291 Irving Hill Drive, Lawrence, KS 66045.

IEEE Log Number 9036043 over, NH, during 1985. This facility has made possible controlled ice growth, detailed ice characterization, and careful control over the relative position between monitoring devices and the ice surface; i.e., parameters such as incidence angle and slant range. Using data collected at CRREL, more precise correlation of backscatter and ice physical parameters (e.g., surface roughness and dielectric constant) are now possible.

As a part of these experiments on saline ice, the Universities of Kansas and Massachusetts and the Environmental Research Institute of Michigan (ERIM) performed radar measurements and collected surface roughness data, and the Universities of Massachusetts and Washington and the Polar oceans group from NORDA performed passive microwave measurements. CRREL personnel conducted ice property studies during the same period, including salinity, temperature, and thickness measurements, and examined the internal structure of the ice.

We collected radar data using both a fine-resolution $C$ band $\mathrm{FM}-\mathrm{CW}$ radar and a $C$-band step-frequency radar. We acquired data over incidence angles from $0^{\circ}$ to $50^{\circ}$ with $V V$ and $H H$ polarizations. The measurements we are reporting here are unique in that they are well calibrated measurements of ice surfaces that are thoroughly characterized statistically.

This paper reports results of the CRREL'88 and CRREL'89 experimental investigations, and comparisons with theory. Several components of the investigation, including the CRREL facility, radars used, measurement program, experimental procedure, and physical characteristics of the ice are discussed in Section II. Section III provides experimental results and comparison with SPM theory predictions. Conclusions are presented in the final section.

\section{Experimental Program}

\section{A. CRREL Facility}

A $12.2 \times 5.2 \mathrm{~m}, 1.5$-m-deep outdoor pond was used to grow artificial sea ice. Radars were mounted on a portable gantry of sufficient width to straddle the pond, so that measurements could be made over the entire pond at various incidence angles. The setup for 1988-1989 is shown in Fig. 1. 


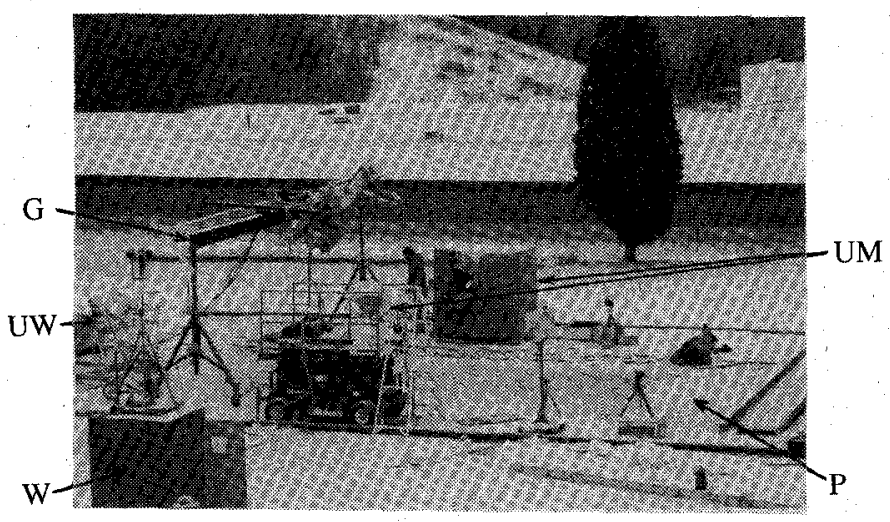

Fig. 1. Experimental setup during CRREL'89. KU and ERIM radars mounted on gantry (G). University of Washington (UW) radiometers and University of Massachusetts (UM) radiometer and radar were installed on mounts located next to pond (P). Weather station (W) is in foreground:

\section{B. Microwave Sensors}

We used a $C$-band FM-CW sensor called PAIR (Polarization Agile Instrumentation Radar), and a Step-frequency radar (STEFRAD) for measurements during the experiments at CRREL. PAIR is a fine-resolution radar that is frequency-modulated over a bandwidth of 500 $\mathrm{MHz}$. This bandwidth provides a free-space range resolution of $30 \mathrm{~cm}$. The bandwidth is adjustable and can be increased to $1 \mathrm{GHz}$. We used a 1-m-diameter antenna with a two-way bandwidth of $3.5^{\circ}$, and it is focused at a 3.5$\mathrm{m}$ range by displacing the feed along its focal axis. The size of the footprint at $3 \mathrm{~m}$ for this system is about $20 \times$ $20 \mathrm{~cm}$. The STEFRAD has a range resolution identical to that of PAIR but has a $1.2 \times 1.2-\mathrm{m}$ footprint at a $3.5-\mathrm{m}$ range because we used wide-beam standard gain horns. Important specifications of these two sensors are given in Table I.

\section{Measurement Procedure}

We performed the backscatter measurements during January $14-15,1988$, on smooth, 10-cm-thick saline ice. After completing the measurements on smooth saline ice, $1 \times 2 \mathrm{~cm}$ ice cubes were dumped on the sheet to simulate rubble field roughness, and data were collected on the roughened surface. During 1989, we collected backscatter data on snow-covered smooth 12 -cm-thick saline ice. After completing the measurements on snow-covered ice, we removed the 7-cm-thick dry fluffy snow layer and acquired data on the bare ice.

\section{Experimental Methodology}

For each of the scenes, we collected data at $0^{\circ}, 10^{\circ}$, $20^{\circ}, 30^{\circ}, 40^{\circ}$, and $50^{\circ}$ for $V V$ and $H H$ polarizations. The gantry height was maintained at approximately $3.3 \mathrm{~m}$, for convenience. For each incidence angle, we made several statistically uncorrelated observations by moving the gantry over the ice surface. We obtained five uncorrelated samples for the smooth and snow-covered surfaces and ten samples for the rough surface. We measured the sys-
TABLE I

IMPORTANT SPECIFICATIONS OF THE SENSORS USED

\begin{tabular}{lcc}
\hline \hline & PAIR & STEFRAD \\
\hline Operating frequency (GHz) & 6.0 & 5.3 \\
RF bandwidth ( $\mathrm{MHz}$ ) & 500 & 500 \\
Free-space range resolution & 30 & 30 \\
$(\mathrm{~cm})$ & $70 \mathrm{~Hz}$ & - \\
Modulation rate & $20 \times 20$ & $120 \times 120$ \\
Footprint in cm (at 3.5 m) & $>50$ & $>70$ \\
Dynamic range (dB) & 10 & 10 \\
Transmit power (mW) & & \\
\hline
\end{tabular}

tem response (internal calibration) after every second or third sample. Backscatter from an 8-in Luneburg lens or an active radar calibrator provided a calibration reference (external calibration).

\section{E. Measured Physical Characteristics of Ice}

The salinity of the pond water was maintained at 24 parts per thousand (ppt) throughout the experiments. Air temperature was continuously monitored at a nearby weather station and readings from a thermistor string provided ice temperature profiles. During the 1987-1988 campaign surface roughness estimates were obtained by analyzing photographs of sections cut from the ice sheet (photographs courtesy of ERIM). In 1988-1989, we determined surface roughness with a wire gauge. We estimated snow surface roughness from photographs and measured snow depth, density, and particle size. For all of the experiments salinity profiles and ice-structure photographs were supplied by CRREL.

The internal structure of the saline ice sheet studied during 1987-1988 is shown in Figs. 2 and 3; it is typical of that of first-year ice growing under calm conditions and is composed principally of columnar crystals. The saline ice sheet studied during 1988-1989 was similar in structure. Salinity profiles at the time of the 1987-1988 saline ice sheet measurements are shown in Fig. 4 and those corresponding to the 1988-1989 saline ice sheet measurements are shown in Fig. 5. These C-shaped profiles are typical of those of thin first-year ice found in the Arctic [8]. Concurrent temperature profiles are shown in Figs. 6 and 7.

We employed the temperature and salinity data to estimate dielectric constant using empirical expressions developed by Frankenstein and Garner [9] and Vant [10]. Dielectric constant is plotted versus ice depth in Figs. 8 and 9 for the 1987-1988 and 1988-1989 ice sheets, respectively.

Surface roughness data for 1987-1988 are tabulated in Table II, while surface roughness, snow density, and snow particle size for 1988-1989 are presented in Table III. In general rough surfaces are characterized by the rms height $\sigma$ and correlation length $I$. Both of these are determined from measured samples of surface height with uniform spacing between samples. In essence, these quantities describe rms height and the frequency with which height is 


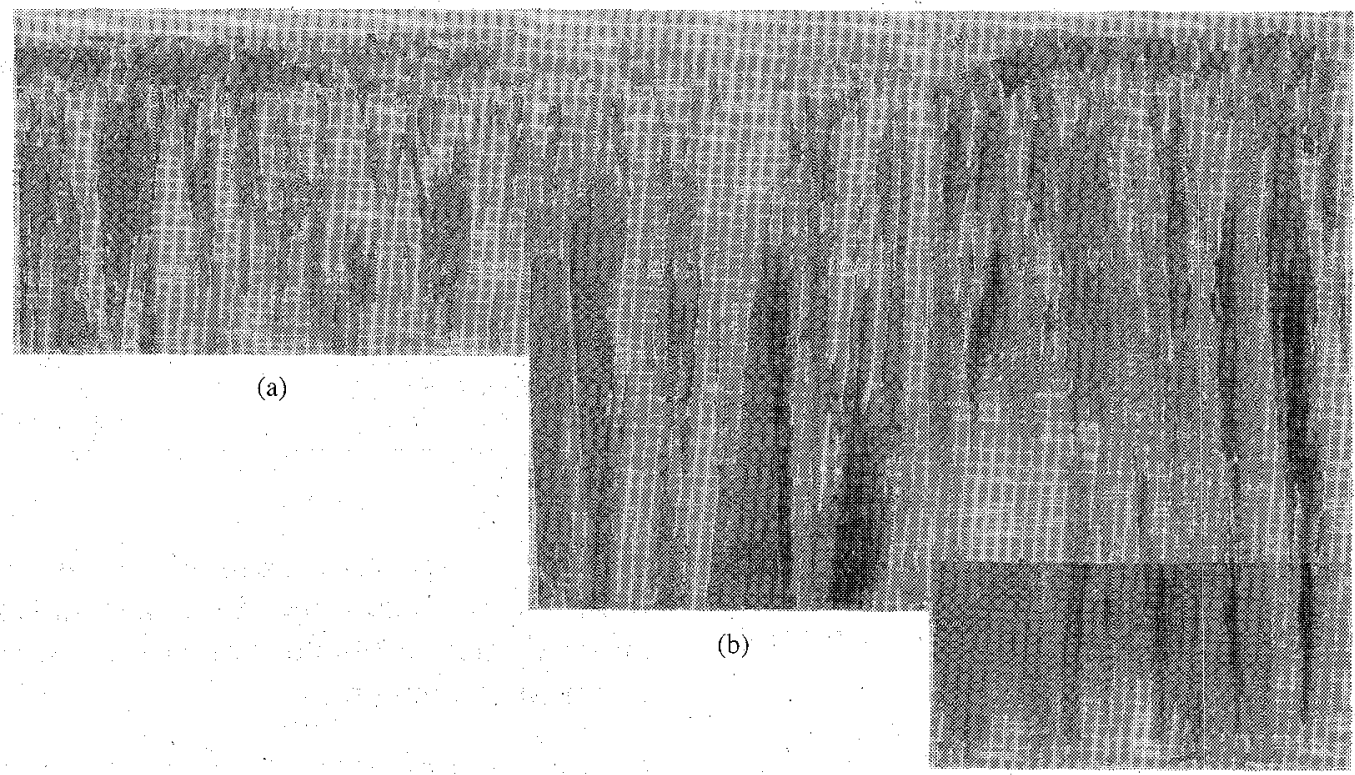

(c)

Fig. 2. Thin section photographs of internal structure of saline ice sheet of CRREL' 88 experiment. (a) January $14: 6.5 \mathrm{~cm}$ after 3 days growth. (b) January 15:11.5 cm after 4 days growth. (c) January $17: 14.5 \mathrm{~cm}$ after 6 days growth.

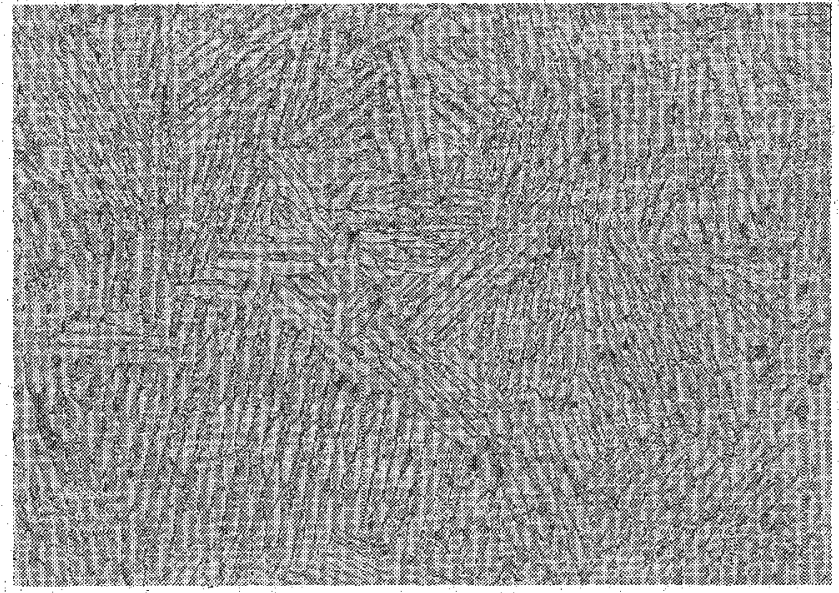

Fig. 3. Platelet structure of crystals at depth of $6 \mathrm{~cm}$ in 6.5 -cm-thick ice.

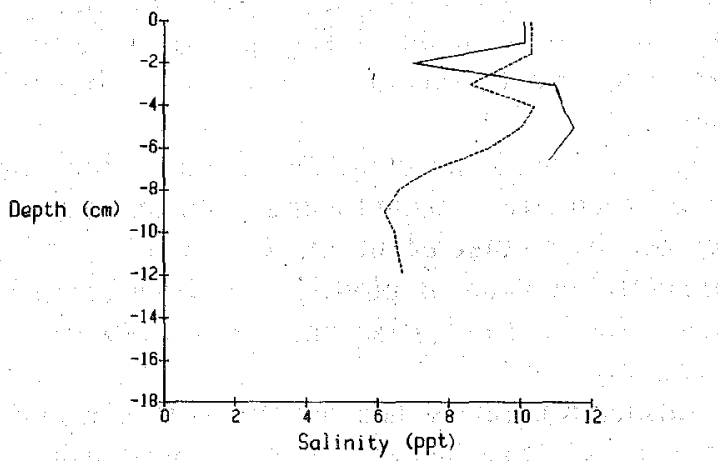

Fig. 4. Salinity profile of saline ice sheet of CRREL'88 experiment. $(-)=$ January $14 .(\cdots)=$ January 15 .

varying as one moves along the surface. Because rms height and correlation length are estimated from a finite number of samples, some uncertainty is associated with

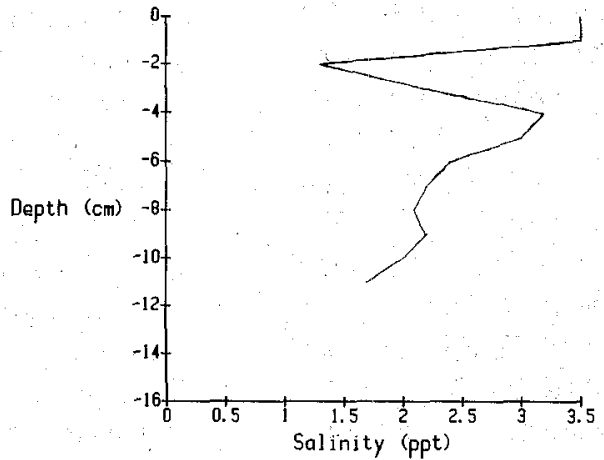

Fig. 5. Salinity profile of saline ice sheet investigated during CRREL' 89 experiment, February 3.

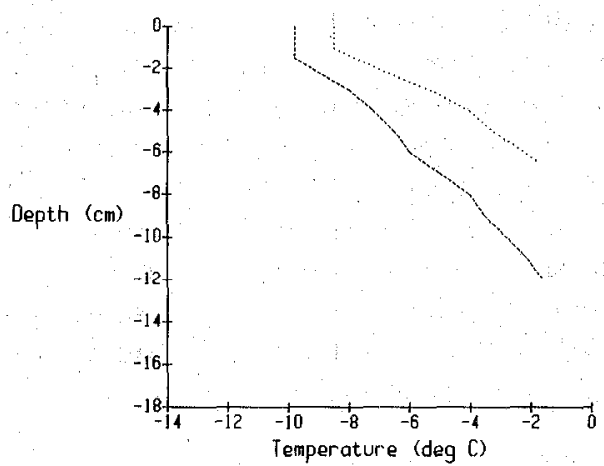

Fig. 6. Temperature profiles of CRREL' 88 ice sheet on days measurements were taken $(\cdots)=$ January $14 .(---)=$ January 15 .

how well they describe the actuall distribution. We computed the average rms height and its associated standard deviation $\Delta \sigma$ and the correlation length and its associated standard deviation $\Delta I$. We assumed rms height as $\sigma+\Delta \sigma$ and the correlation length as $I-\Delta I$ for computing the 


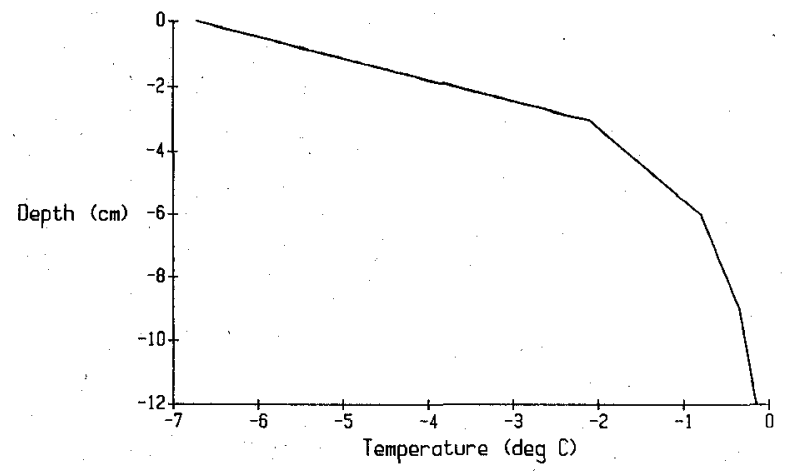

Fig. 7. Temperature profile of saline ice sheet grown during CRREL'89 experiment on day measurements were performed, February 3.

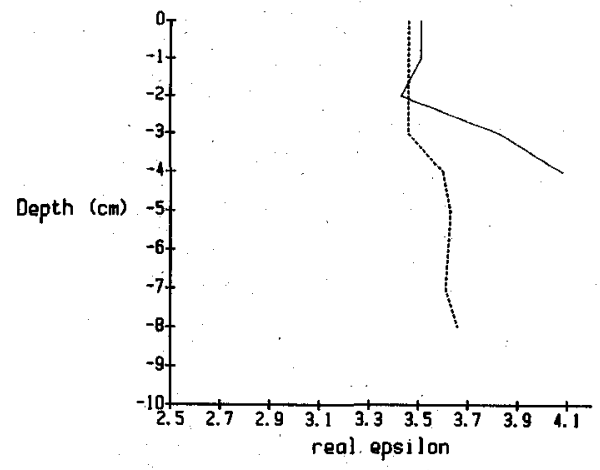

(a)

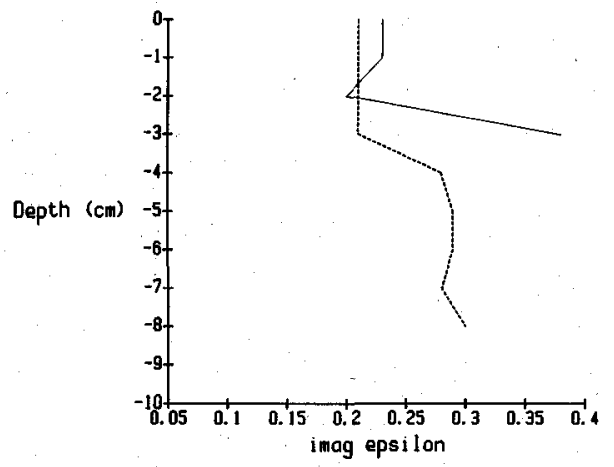

(b)

Fig. 8. Estimated dielectric constant profiles at $C$ band for CRREL' 88 ice sheet. (a) Real part. (b) Imaginary part. $(-)$ January 14. (---)= January 15 .

maximum value predicted by the theory, and rms height as $\sigma-\Delta \sigma$ and the correlation length as $I+\Delta I$ for computing the minimum value predicted by the theory as shown in Section III.

\section{Data Analysis and Results}

\section{A. Smooth Saline Ice}

Backscatter from a smooth saline ice sheet at $C$-band is shown in Fig. 10. The solid curve represents a minimum mean-square-error polynomial fit to the data. The bars represent statistical measurement uncertainty. The two dotted curves indicate the maximum and minimum small perturbation method (SPM) predictions [11] of $\sigma^{\circ}(\theta)$ based on the rms height \pm 1 standard deviation and the correlation length \pm 1 standard deviation of the surface.

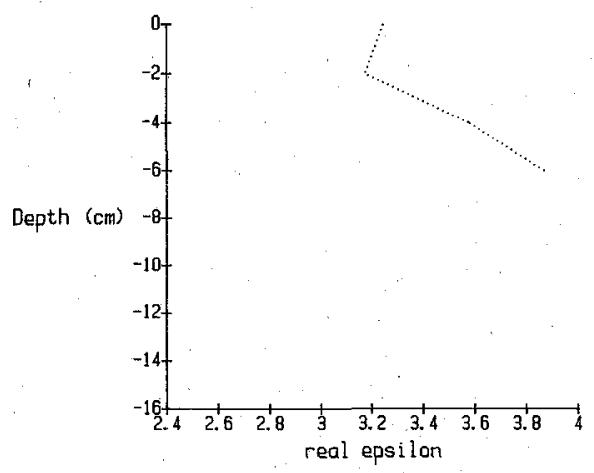

(a)

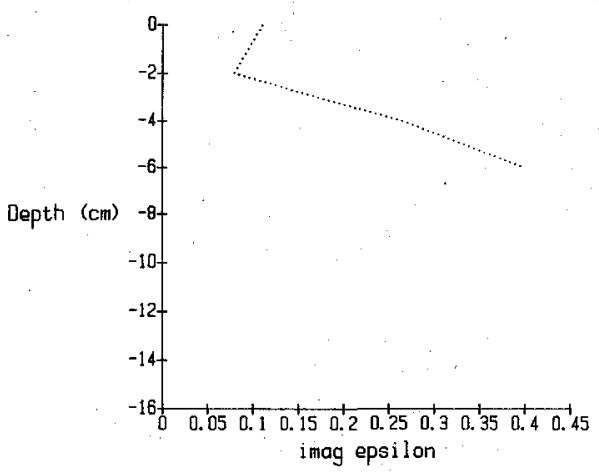

(b)

Fig. 9. Estimated dielectric constant profiles at $C$ band for CRREL' 89 ice sheet, February 3. (a) Real part. (b) Imaginary part.

The dashed line indicates the noise level of the STEFRAD radar. This includes system noise and coherent contributions due to the wide beamwidth of the STEFRAD antenna. The radar used in the experiment did not have the sensitivity to measure the $\sigma^{\circ}(\theta)$ predicted by SPM. However, the measured $\sigma^{\circ} s$ are still several $\mathrm{dB}$ above noise level. We have compared our surface roughness measurements with those obtained by the ERIM group and have found the two to be in reasonable agreement. The uncertainty in our surface roughness measurements does not appear to be of sufficient matgnitude to have caused the large discrepancy between backscatter measurements and SPM predictions. Therefore, the discrepancy between measurement and SPM theory can be attributed to the presence of scattering from beneath the surface, since SPM computes only the surface scatter component.

To illustrate the subsurface scattering effect, we constructed a simple model in which the scattering is assumed to originate from an equivalent rough interface beneath the surface. Such an approach cannot be justified rigorously. Our goal in constructing the model is to show the presence of subsurface scatter, not to develop theoretical models of scattering. This simple model, we believe, is justified in light of the abrupt change in dielectric constant at depths of 2-4 cm observed on February 3, 1989 (see Fig. 9). We can model this layer as [11]

$$
\sigma^{\circ}(\theta)=T^{2}(\theta) \sigma_{\text {es }}^{\circ}\left(\theta^{\prime}\right)\left(\exp \left(-2 \alpha d \sec \theta^{\prime}\right)\right)+\sigma_{\text {ice }}^{\circ}(\theta)
$$




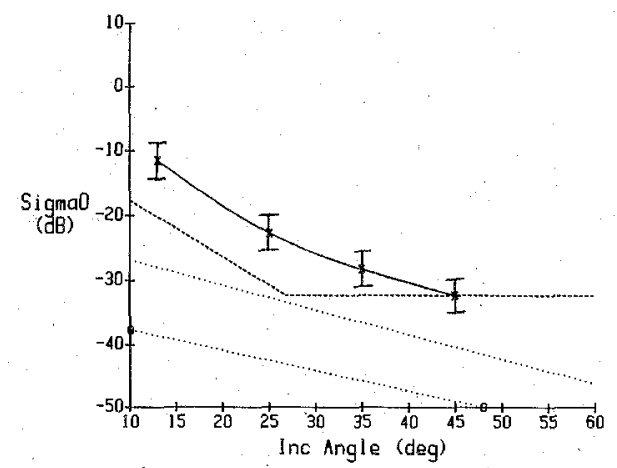

Fig. 10. Experimental and theoretical backscatter cross sections of smooth saline ice sheet at $C$ band ( $\sigma$ and $l$ describe surface roughness; rms height $\sigma=0.024 \mathrm{~cm}$, correlation length). $l=1.2 \mathrm{~cm} .(-)=$ Fit to $C$-band $H H$ polarization data. ( $(*)$ $=C$ band $H H$ polarization. $(0 \cdots \cdot 0)=$ Theory minimum. $(\cdots)=$ Theory maximum. $(---)=$ Radar system effects.

TABLE II

SURFACE CHARACTERISTICS FOR CRREL'8 8 EXPERIMENT"

\begin{tabular}{lccccc}
\hline Surface & RMS Height & $\begin{array}{c}\text { SD of } \\
\text { RMS Height }\end{array}$ & $\begin{array}{c}\text { Correlation } \\
\text { Length }\end{array}$ & $\begin{array}{c}\text { Correlation } \\
\text { Length } \\
(+1 \text { SD })\end{array}$ & $\begin{array}{c}\text { Correlation } \\
\text { Length } \\
(-1 \text { SD })\end{array}$ \\
\hline $\begin{array}{c}\text { Smooth saline ice } \\
\text { January 14 } \\
\text { Roughened saline ice } \\
\text { January 15 }\end{array}$ & 0.029 & 0.01 & 1.77 & 0.81 & 2.49 \\
\hline
\end{tabular}

${ }^{a}$ All dimensions in $\mathrm{cm}$ unless otherwise indicated.

${ }^{b}$ Standard deviation.

TABLE III

Ambient Conditions and SURFACE Characteristics for CRREL' 89 EXPERIMENT, FEBRUARY $3^{a}$

\begin{tabular}{|c|c|c|c|c|c|}
\hline & Air Temperature & $\begin{array}{l}\text { Ambient Conditi } \\
\text { Solar Radiation }\end{array}$ & \multicolumn{2}{|c|}{ Snow Settling T'ime } & \\
\hline & $\approx-10^{\circ} \mathrm{C}$ & $\approx 0$ (night $)$ & \multicolumn{2}{|c|}{$\approx 2$ hours } & \\
\hline & \multicolumn{4}{|c|}{ Characteristics of Saline Ice Surface } & \\
\hline RMS Height & $\begin{array}{c}\mathrm{SD}^{b} \text { of } \\
\text { RMS Height }\end{array}$ & $\begin{array}{c}\text { Correlation } \\
\text { Length }\end{array}$ & \multicolumn{2}{|c|}{$\begin{array}{c}\text { Correlation } \\
\text { Length } \\
(+1 \text { SD })\end{array}$} & $\begin{array}{c}\text { Correlation } \\
\text { Length } \\
(-1 \text { SD })\end{array}$ \\
\hline 0.024 & 0.012 & 1.2 & \multicolumn{2}{|c|}{1.1} & 1.46 \\
\hline & \multicolumn{4}{|c|}{ Characteristics of Snow Cover } & \\
\hline $\begin{array}{l}\text { Mean } \\
\text { Particle Size }\end{array}$ & Density & Wetness & $\begin{array}{c}\text { Surface } \\
\text { RMS Height }\end{array}$ & $\begin{array}{l}\text { Surface } \\
\text { Corr Length }\end{array}$ & $\begin{array}{l}\text { Brine } \\
\text { Content }\end{array}$ \\
\hline $0.1 \times 0.2 \mathrm{~cm}$ & $\begin{array}{l}0.06 \mathrm{~g} / \mathrm{cm}^{3} \\
\text { (near snow sur }\end{array}$ & $\therefore<5 \%$ & $0.28 \mathrm{~cm}$ & $1.8 \mathrm{~cm}$ & small' \\
\hline
\end{tabular}

\footnotetext{
${ }^{a}$ All dimensions in cm unless otherwise indicated.

Standard deviation:

"When removing snow from the surface, we observed that the ice surface was dry to the touch and that no apparent melting had occurred.
}

where

$\alpha$
$T^{2}(\theta)$ air-ice transmission coefficient assuming a smooth interface,

$d \quad$ depth of the equivalent surface in the ice;

$\theta^{\prime} \quad$ angle of refraction in saline ice,

$\theta \quad$ incidence angle, stant,

power absorption coefficient of the ice calculated using the estimated dielectric con- 


\section{$\sigma_{\text {ice }}^{\circ}(\theta)$ scattering coefficient of the ice surface deter- mined from SPM, \\ $\sigma_{\text {es }}^{\circ}\left(\theta^{\prime}\right)$ scattering coefficient of the equivalent surface determined from SPM.}

Results of the model predictions along with experimental data are shown in Fig. 11. We used equivalent rough surface parameters of $\epsilon_{r t}^{\prime}=\left(\epsilon_{\operatorname{med} 2}^{\prime} / \epsilon_{\text {medl }}^{\prime}\right) \leq 1.2, \sigma_{\text {rms }}=$ $0.5 \mathrm{~cm}$, and $l=1.8 \mathrm{~cm}$ for computation, where $\epsilon_{r t}^{\prime}$ is the permittivity ratio at the interface, $\sigma_{\mathrm{rms}}$ is the surface rms height, and $l$ is the surface correlation length.

The model predictions are fairly close to the measured data and confirm the hypothesis that the volume scatter contribution must be taken into account for developing scattering models for a smooth ice surface at $C$-band. $\sigma^{\circ}$ for this ice sheet was similar in level to that observed for first-year ice in Mould Bay [12], with the exception that $\sigma^{\circ}$ for the CRREL ice sheet decreased more rapidly as a function of incidence angle, because of its very smooth surface.

\section{B. Snow-Cover Effects}

A 7-cm-deep snow cover on the smooth saline ice sheet drastically altered the $\sigma^{\circ}$ of bare ice. At incidence angles greater than $25^{\circ}$, the $\sigma^{\circ}$ of snow-covered ice was about 7 $\mathrm{dB}$ higher than that for bare ice. Also, the presence of snow caused a large reduction in $\sigma^{\circ}$ at $13^{\circ}$ incidence, as shown in Fig. 12. At large incidence angles the increase in $\sigma^{\circ}$ of snow-covered ice is the result of a contribution to the backscattered signal from the snow volume. Three possible reasons exist for the reduction at angles near vertical. First, it could have been caused by scattering from the rough snow surface. Although the snow surface was rougher than the bare ice surface, surface scattering at the snow-air interface was small because of the low snow dielectric constant $\left(\epsilon_{r}^{\prime}=1.2\right)$. Second, the ice surface properties were altered in the process of removing the snow (we studied the snow-covered surface prior to the bare ice surface). However, we found no evidence that the snow cover modified the ice surface or that we altered the ice surface in the process of shoveling and sweeping snow; the ice surface was dry and naturally smooth after the snow was removed (the conditions at the time of the measurement were ice salinity of $3 \mathrm{ppt}$; dry snow, and a cold temperature of $-10^{\circ} \mathrm{C}$ ). Furthermore, we had little difficulty removing the snow all the way down to the ice surface. A third possibility is that the snow may have been acting as an impedance matching layer. Normally, a thin layer of snow settles to a nearly uniform density within a period of a few hours after it falls [13]. We studied the snow-covered ice sheet less than $2 \mathrm{~h}$ after the snow fell. If only partial settling had occurred, it could have been that the density of the snow varied as a function of depth, thus forming a layer with a tapered impedance. Such a layer could have caused partial matching over the wide RF bandwidth of our radar and caused the reduction at angles near vertical. We cannot prove that this tapering actually existed because we did not measure snow density

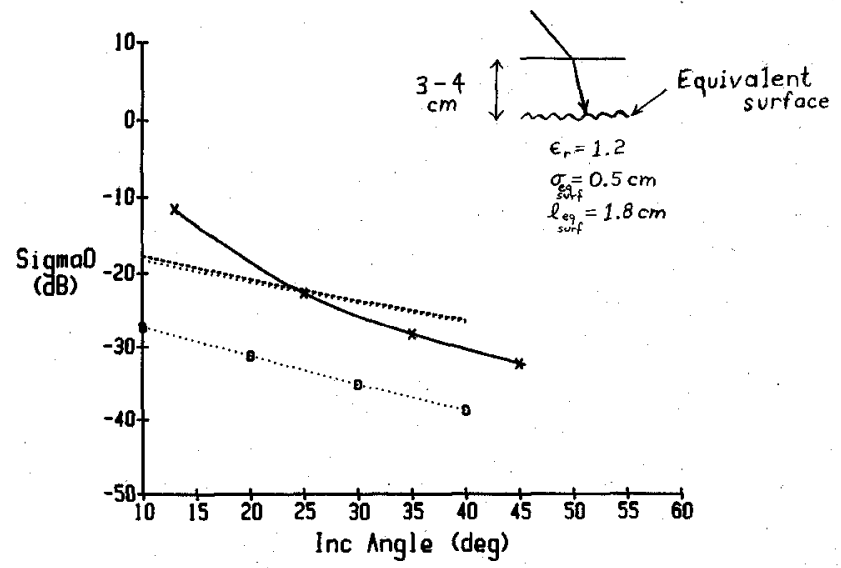

Fig. 11. Comparison of simple layer model predictions with measurements for saline ice investigated during CRREL'89. ( -$)=$ Fit to $C$-band $H H$ polarization data. $(\times)=C$-band $H H$ polarization. $(0 \cdots 0)$ $=$ Surface. $(\cdots)=$ Equivalent surface. $(\cdots)=$ Surface plus equivalent surface.

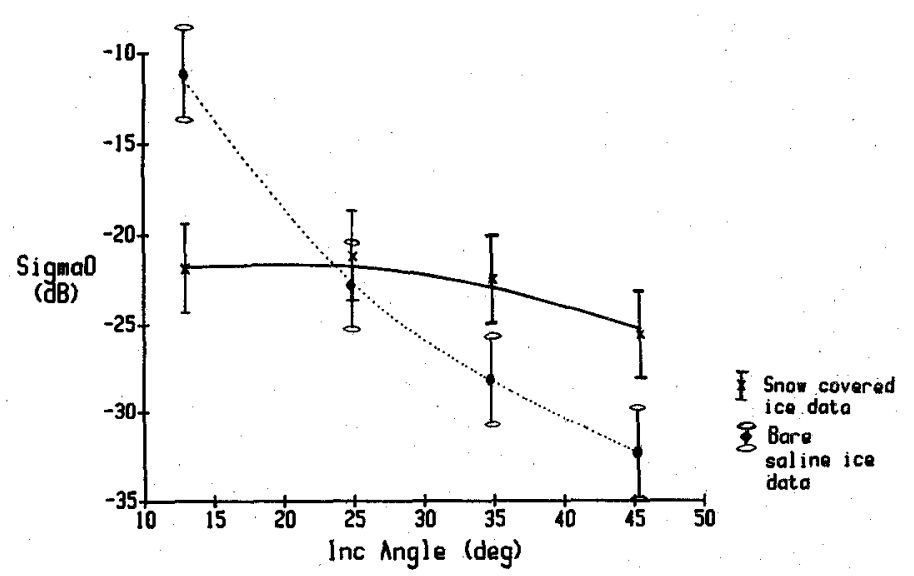

Fig. 12. Effect of 7-cm snow cover on backscatter from smooth saline ice. $\sigma_{\text {snow }}=0.28 \mathrm{~cm}, l_{\text {snow }}=1.8 \mathrm{~cm}$, snow depth $=7 \mathrm{~cm}, \sigma_{\text {ice }}=0.024 \mathrm{~cm}$, $l_{\text {ice }}=1.2 \mathrm{~cm} .(\stackrel{(}{-})=$ Fit to snow-covered saline ice data. $(\cdots)$ $=$ Fit to bare saline ice data.

as a function of depth, but only state that it appears to have been a possibility. That is, we suspect that the snow layer was still in a state of settling and therefore nonuniform because of the unusually low density near the snow surface $\left(0.06 \mathrm{~g} / \mathrm{cm}^{-3}\right.$ as opposed to more typical densities of $>0.1 \mathrm{~g} / \mathrm{cm}^{-3}$, e.g., [14]). Such low snow densities and a large reduction in $\sigma^{\circ}$ near nadir due to snow cover are not generally observed in the Arctic.

We applied the layer model reported by Ulaby et al. [11] to show that the increase in backscatter from snowcovered ice at large incidence angles is because of volume scatter from snow. This layer model has the form:

$$
\begin{aligned}
\sigma^{\circ}(\theta)= & T^{2}(\theta)\left[\sigma_{\mathrm{ds}}^{\circ}\left(\theta^{\prime}\right)+\left(\sigma_{\text {ice }}^{\circ}\left(\theta^{\prime}\right) / L^{2}\left(\theta^{\prime}\right)\right)\right] \\
& +\sigma_{\text {snow surf }}^{\circ}(\theta)
\end{aligned}
$$

where
$T^{2}(\theta)$
transmission coefficient of the air-snow interface,
$L\left(\theta^{\prime}\right) \quad \exp \left(k_{e} d \sec \left(\theta^{\prime}\right)\right)$, 


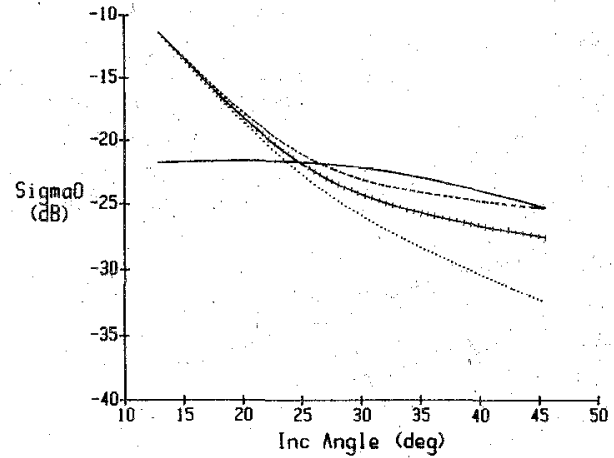

Fig. 13. Comparison of model predictions with snow covered ice measurements. Measurements same as for Fig. 12. (-) = Fit to snowcovered ice data. $(\cdots)=$ Fit to bare saline ice data. $(+++)=$ Predicted with $0.05 \mathrm{~g} / \mathrm{cm}^{3}$ snow. $(--)=$ Predicted with $0.1 \mathrm{~g} / \mathrm{cm}^{3} \mathrm{~cm}$ snow.

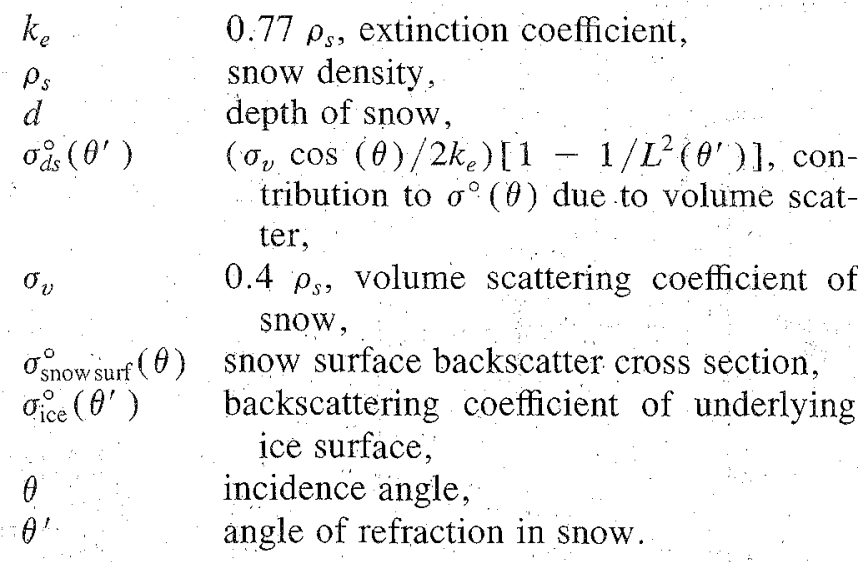

Fig. 13 shows predicted $\sigma^{\circ}$ for the combincd surface using $\rho_{s}=0.05 \mathrm{~g} / \mathrm{cm}^{3}$ and $0.1 \mathrm{~g} / \mathrm{cm}^{3}$ (measured value of $\rho_{s}$ was $0.06 \mathrm{~g} / \mathrm{cm}^{3}$ ). Notice that the magnitude of the return is well predicted for $\rho_{s}=0.1 \mathrm{~g} / \mathrm{cm}^{3}$ except at incidence angles less than $25^{\circ}$. Fig. 14 illustrates the relative contributions to $\sigma^{\circ}$ by the snow surface, snow volume, and ice for $\rho_{s}=0.1 \mathrm{~g} / \mathrm{cm}^{3}$. The surface term is about $10 \mathrm{~dB}$ lower than the volume term at incidence angles larger than $30^{\circ}$. This confirms the earlier statement that surface scatter from snow is low because of low dielectric contrast at the air-snow interface. The agreement between measured and model predictions (combined volume + surface) is fairly close except at the $13^{\circ}$ incidence. With the exception of $13^{\circ}$ incidence, $\sigma^{\circ}$ for this ice sheet was similar in level to that observed for snow-covered first-ycar ice in Mould Bay [15].

\section{Rough Saline Ice}

During the 1987-1988 experiment, we also made measurements of backscatter on rough ice simulated by dumping $1 \times 2-\mathrm{cm}$ ice cubes on the surface. The measured rms height and correlation. length of the rough ice were 0.45 and $0.98 \mathrm{~cm}$, respectively. The radar returns from rough ice were about $15 \mathrm{~dB}$ higher than those for smooth ice at incidence angles greater than $30^{\circ}$, as shown in Fig. 15 . In fact the returns from rough ice were higher than those from desalinated ice. The results of measurements on de-

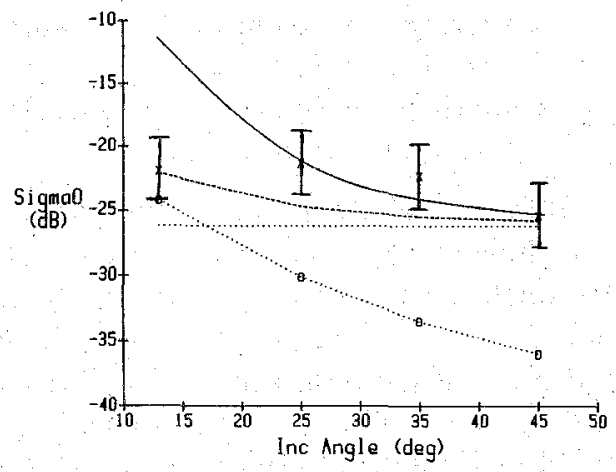

Fig. 14. Measured backscatter cross sections of snow-covered saline ice and predicted relative contributions from snow surface, snow volume, and ice surface. $(-)$ Total predicted. $(\$)=$ Snow-covered ice data. $(0 \cdot \cdots 0)=$ Snow surface (predicted). $(\cdots \cdot)=$ Snow volume (predicted) $(---)=$ Snow volume plus surface $($ predicted).

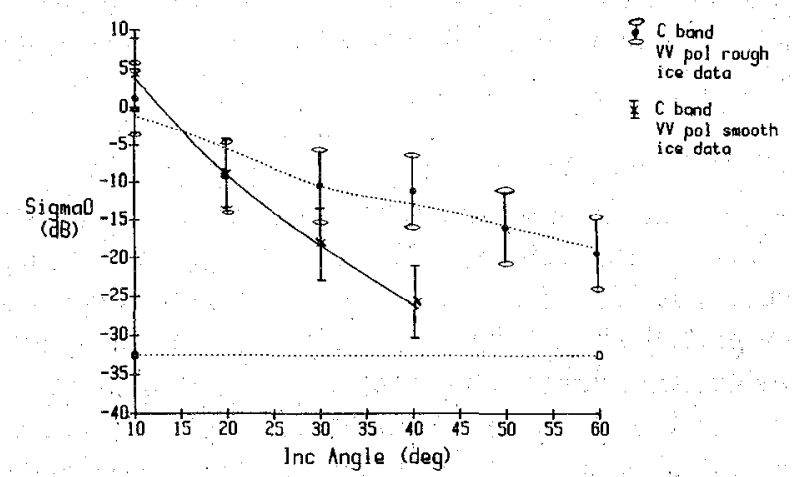

Fig. 15. Comparison of backscatter cross sections of smooth saline and rough saline ice. $(\cdots)=$ Fit to $C$-band $V V$ polarized rough ice data. $(\div)=$ Fit to $C$-band $V V$ polarized smooth ice data. $(0 \cdots 0)=$ Radar system effects.

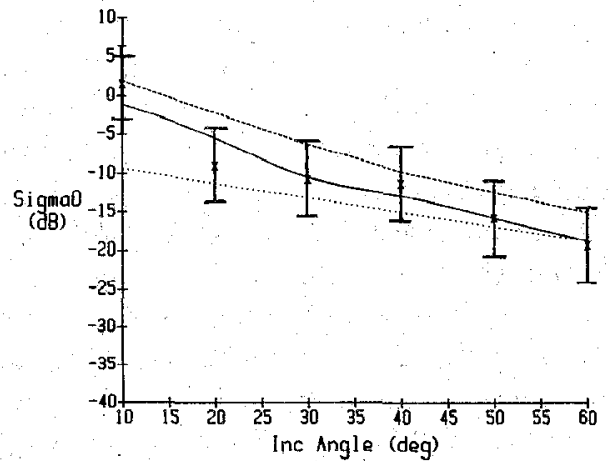

Fig. 16. Experimental and theoretical backscatter cross sections of rough saline ice investigated during CRREL' 88 experiment. $\sigma=0.45 \mathrm{~cm} . l=$ $1 \mathrm{~cm} .(-)=$ Fit to $C$-band $V V$ polarized rough ice data. $\left(\begin{array}{l}* \\ -\end{array}\right) C$ band $V V$ polarization, rough $(\cdots)=$ Theory minimum. $(--)=$ Theory maximum

salinated ice are not presented here since it is a topic of another paper.

Fig. 16 shows the measured results and SPM predictions for rough ice. The validity conditions (i.e., $k \sigma<$ 0.3 and $(\sqrt{2} \sigma) / l<0.3)$ for SPM were not satisfied in this case, $k \sigma \cong 0.56$ and $(\sqrt{2} \sigma) / l \cong 0.6$. Nevertheless; it predicts the backscatter measured over the entire range 
as shown in Fig. 16. Chen [13] computed the scattering for these conditions using method of moments solutions. The results from his simulations show that the difference between SPM predictions and method of moments solutions to be less than $2 \mathrm{~dB}$ for this particular set of conditions (i.e., $k \sigma<0.5$ and $(\sqrt{2} \sigma) / l<0.5$ ). We did not use the physical optics formulation under scalar approximation since it does not accurately predict $V V$ polarization for incidence angles greater than about $40^{\circ}[11]$ and because the pertinent validity conditions were not satisfied. We did not have access to any field data sets under similar conditions to compare with this data set.

\section{Summary and CONClusion}

We performed backscatter measurements at $C$-band on smooth, rough, and snow-covered smooth saline ice. In the investigation we came to the following conclusions.

1) The volume scatter contribution to backscatter from smooth ( rms height $<0.05 \mathrm{~cm}$ ) saline ice cannot be neglected. We were unable to quantify the relative surface and volume contributions, but our results indicate that the volume contribution is comparable to the surface contribution.

2) A thin dry snow layer greatly altered the measured backscatter cross section of smooth saline ice at incidence angles greater than about $25^{\circ}$. A large reduction in $\beta^{\circ}$ near nadir was due to a set of circumstances atypical of conditions in the Arctic.

3) Backscatter from moderately rough saline ice is dominated by the contribution from the surface. and volume contribution can be ignored. For the rough surface, we observed that the small perturbation method correctly predicted the measured data over incidence angles of 0 $60^{\circ}$.

\section{ACKNOWLEDGMENT}

The authors would like to thank Prof. A. Fung for many helpful suggestions during the course of this investigation, Dr. A. Gow from the CRREL for supplying data on thin sections, salinity, and temperature, and Dr. R. Onstott from the ERIM for supplying surface roughness data. We would also like to express our thanks to D. Graham for help in preparing this paper.

\section{REFERENCES}

[1] V. H. Anderson, "High altitude, side-looking radar images of sea ice in the Arctic," in Proc. 4th Symp. on Remote Sensing of the Environment (Ann Arbor, MI), 1966, pp. 845-857.

[2] J. W. Rouse, "Arctic ice type identification by radar," Proc. IEEE, vol. 57, no. 4; pp. 605-614, 1969 .

[3] J. D. Ketchum, Jr., and S. G. Tooma, Jr., "Analysis and interpretation of air-borne multifrequency side-looking radar sea imagery,' J. Geophys. Res., vol. 78, no. 3, pp. 520-538, 1973.

[4] J. D. Johnson and L. D. Farmer, "Use of side-looking air-borne radar for sea ice identification,"J. Geophys. Res., vol. 76, no. 9, pp. 21382155,1971

[5] B. B. Hagman, "On the use of microwave radiation for Great Lakes for surveillance," Great Lakes Environmental Res. Lab. Ann Arbor, MI, NOAA Tech. Memo. ERL GLERL-13, 1976.
[6] R. T. Gedney et al., "All weather ice information system for Alaskan coastal shipping," in Proc. 9th Annu. Offshore Technology Conf. (Houston, TX), 1977, pp. 299-306.

[7] V. S. Loshchilov, A. D. Masanov, and I. G. Serebrennikov, "The use of SLAR for the mapping of sea ice and the study of ice dynamics," publishing information unknown, ca. 1978.

[8] J. Bredow, S. P. Gogineni, A. J. Gow, P. F. Blanchard, and R. K. Moore, "Radar backscattering from artificially grown sea ice," IEEE J. Oceanic Eng., vol. 14, pp. 259-264, July 1989.

[9] G. Frankenstein and R. Garner, "Equation for determining the brine volume of sea ice from $-0.5^{\circ} \mathrm{C}$ to $-22.9^{\circ} \mathrm{C}, " J$. Glaciology, vol. 6, pp. 943-944, 1967

[10] M. R. Vant, "A combined empirical and theoretical study of the dielectric properties of sea ice over the frequency range $100 \mathrm{MHz}$ to 40 GHz," Ph.D. dissertation, Carlton Univ., 1976.

[11] F. T. Ulaby, R. K. Moore, and A. K. Fung, Microwave Remote Sensing: Active and Passive, vol. II. Norwood, MA: Artech House, 1982.

[12] R. G. Onstott and R. K. Moore, "C-band measurements of radar backscatter from ice-project summary report," Univ. of Kansas Center for Research, Lawrence, RSL Tech. Rep. TR 524-Final, 1983.

[13] A. J. Gow, personal correspondence, 1989.

[14] M. Hallikainen, F. T. Ulaby, and M. Abdelrazik, "Measurements of the dielectric properties of snow in the 4-18-GHz frequency range," Univ. of Kansas Center for Research, Lawrence, RSL Tech. Rep. TR 527-3, 1982.

[15] Y. S. Kim, R. K. Moore, and R. G. Onstott, "Theoretical and experimental study of radar backscatter from sea ice," Univ. of Kansas Center for Research, Lawrence, RSL Tech. Rep. TR 331-37, 1984.

[16] K. Chen, "Rough surface scattering by integral equation method with application to sea surface: An iterative approach," Ph.D. dissertation proposal, Univ. of Texas at Arlington, 1989.

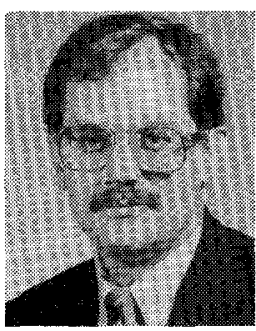

Jonathan W. Bredow received the B.S.E.E. degree from Kansas State University, Manhattan, the M.S.B.M.E. degree from Iowa State University, Ames, and the Ph.D. degree from the University of Kansas, Lawrence, in 1977, 1980, and 1989 respectively. From 1985 to 1987 , at the Radar Systems and Remote Sensing Laboratory of the University of Kansas, he conducted research on radar return from various types of vegetation. From 1987 to 1989 , he studied microwave backscatter from sea ice. Since 1989 , he has been involved with laboratory measurements of machined targets, as part of a program to determine mechanișms of scattering. He is currently an Assistant Professor in the Department of Electrical Engineering at the University of Texas, Arlington.

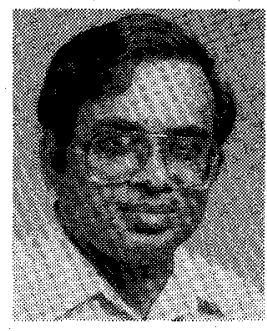

Sivaprasad Gogineni received the Ph.D. degree from the University of Kansas, Lawrence.

He is currently an Associate Professor in the Department of Electrical and Computer Engineering at the University of Kansas. He has been involved in research on the application of radars to the remote sensing of sea ice, ocean and land. He has authored or been a coauthor of 14 papers and several technical reports and conference presentations. He was actively involved in developing instrumentation for radar systems currently being used at the University of Kansas for backscatter measurements. He has also participated in field experiments in the Arctic and on towers in the open ocean. Currently, he is working on computer graphics packages for teaching electromagnetics' and on developing millimeter-wave radars for scattering measurements. 